\begin{abstract}
Romeo-Gabriel Mihaila*
Faculty of Medicine, „Lucian Blaga” University of

Sibiu, Hematology Department, Emergency County,

Clinical Hospital Sibiu, Sibiu, Romania

Dates: Received: 13 July, 2015; Accepted: 11

August, 2015; Published: 14 August, 2015

*Corresponding author: Romeo-Gabriel Mihaila,

Faculty of Medicine, „Lucian Blaga” University of

Sibiu, Sibiu, Romania, Tel: +40-726-340-655; Fax:

+40-269-218365; E-mail: romeomihaila@yahoo.com

www.peertechz.com
\end{abstract}

ISSN: 2455-8591

Keywords: BRAF V600E; Cladribine; Hairy cell; Leukemia; Rituximab

\author{
Case Report
}

\section{Are Cladribine and Rituximab Enough for the Treatment of Relapsed Hairy Cell Leukemia?}

\begin{abstract}
Introduction: Hairy cell leukemia is a rare B-cell lymph proliferation with long-term survivals, in general. Although therapeutic possibilities have progressed over time, many patients have recurrences and the disease can become resistant to treatment. Discovering the BRAF V600E and other genetic mutations and some pathogenetic mechanisms disruptions open new therapeutic horizons.

Case presentation: We present a female patient to which the disease has been monitored for 14 years, during which she has been treated with alpha-interferon, cladribine and rituximab. The monitorization and conduct of such patients are discussed, and an analysis of the therapeutic
\end{abstract} possibilities at this stage is performed, which can be useful for physicians and researchers.

Conclusion: An individual assessment of patient at diagnosis and during evolution is needed to determine which drug or drug combination is indicated and how many therapeutic lines are needed.

\section{Abbreviations}

HCL: Hairy Cell Leukemia; HCL-v: Variant form of hairy Cell Leukemia; IgVH: Immunoglobulin Variable Heavy Chain; NF-kB: Nuclear Factor kappa-light-chain-enhancer of activated B cells;

\section{Introduction}

Hairy cell leukemia (HCL) has been known as a clinic pathological entity for over 50 years [1]. It is a B-cell lymph proliferation which represents $2 \%$ of all leukemias [2]. In France, its incidence is estimated to be about 175 [3]. It occurs more frequently in males (male / female ratio is 3.7), and the median age is considered to be about 55 years [4]. This diagnosis can be suspected to a pale patient, with or without fever or bleeding syndrome, which has splenomegaly. Complete blood counts frequently show pancytopenia, the blood smear and immunophenotyping (realized in blood or bone marrow) establish the presence of hairy cells - atypical lymphoid cells with hairy projections [5] which are positive for CD11c, CD25, CD103 and CD123 [3], and bone marrow examination finds the presence of fibrosis. Sometimes, immunohistochemistry examination could be useful by signaling the presence of tartrate acid-resistant phosphatase in the form of granular cytoplasm, and the positivity of CD20 and CD72 expression [3].

This entity must be differentiated from aplastic anemia [6] and variant form of HCL (HCL-v) (a disease that is distinct from HCL, which represents only $10 \%$ of all cases of HCL, where leukocytosis is common, $\mathrm{CD} 25$ or CD123 are poorly expressed [3], and MAP2K1 gene mutations can be present [7]), splenic diffuse red pulp small B-cell lymphoma [7] (where frequently can be found lymphocytosis and a little or an absent expression of CD25 and CD123, 7q deletion, and mutation in immunoglobulin variable heavy chain gene profile, with VH3-26 and VH4-34 over-represented use [3]), and splenic and other marginal zone lymphoma [8].
Relatively recently, a mutation which is present in almost all cases of classic HCL and which represents a marker of this disease was found: V600E, located in the exon 15 of BRAF gene; it is negative in most other B-cell lymphoproliferations, including the HCL-v [3, 9] and in splenic red pulp lymphoma [3]. But the expression of this mutation was identified in a study, by immunohistochemistry, in $2 \%$ of 44 patients with splenic marginal zone lymphomas [10]. It is also very interesting that $B R A F$ V600E mutation is not present in cell lines obtained from HCL patients, but these cells have the characteristic piliferous morphology and immunophenothype of HCL cells [11]. This raises the issue of possible involvement of other mutations and pathogenetic mechanisms in disease appearance and development, too, some of which have recently been discovered.

The presented case illustrates the evolution of therapeutic possibilities in this lymphoproliferation and creates the opportunity to discuss progress in the field and future therapeutic conduct.

\section{Case Presentation}

A female patient, aged 61, was diagnosed in 2001 with hairy cell leukemia in Hematology Department of Emergency County Clinical Hospital Sibiu, Romania. Then, she presented asthenia, fever (which proved to be without microbiological documentation), pancytopenia, splenomegaly, marrow fibrosis. Bone marrow biopsy and immunohistochemistry supported the diagnosis. She was treated with alpha-interferon (3MIU 3 times per week) during the first year, but it was bad tolerated due to the alopecia and depression. At the end of the first year of treatment she still had 3\% hairy cells in the bone marrow. She continued with a course of cladribine (continuous daily intravenous infusion of $0.1 \mathrm{mg} / \mathrm{kg}$, for 7 days), which became available in Romania since then, after which complete remission has been obtained. The first relapse appeared 4 years later and was also treated with cladribine (but in dose of $0.14 \mathrm{mg} / \mathrm{kg} / \mathrm{day}$, 
subcutaneously, for 5 days), followed by another complete remission. After another three years leucopenia with neutropenia $\left(930 / \mathrm{mm}^{3}\right)$ occurred, but the patient refused a new bone-marrow biopsy and peripheral blood examination has not revealed the presence of hairy cells. She accepted to receive intermittent treatment with filgrastim in periods of increased epidemiological risk, which produced her bone pain. Only after five years she agreed a new bone marrow biopsy, which shown the presence of $50 \%$ hairy cells on the background of a bone marrow cellularity of $50 \%$. Immunohistochemistry confirmed the presence of hairy cells. We considered that the patient had symptomatic disease, due to the neutropenia and frequent infections in the recent past. She received a new course of cladribine $(0.14$ $\mathrm{mg} / \mathrm{kg} / \mathrm{day}$, subcutaneously, for 5 days), followed by acyclovir and sulfamethoxazole + trimethoprim (for the prophylaxis of infections with herpes virus or pneumocystis jiroveci), and also followed by filgrastim, due to the risk of febrile neutropenia. She continued with rituximab ( $375 \mathrm{mg} / \mathrm{m}^{2} /$ dose, monthly), when the approval for this medicine was obtained, for 6 months. The bone marrow biopsy examination, made at the end of this treatment, shown a cellularity of $25 \%$ (with a moderate hypoplasia of granulocyte series), without hairy cells. The patient remained under clinical and biological surveillance.

\section{Discussion}

The fact that our patient had fever at onset of the disease is explained by neutropenia and immune deficiency. These manifestations are frequently present in HCL. In a prospective study made on 49 patients with chronic idiopathic and 27 with autoimmune neutropenia with a median surveillance of 5 years, 4 of them were diagnosed with HCL during the follow-up [12]. The patients with $\mathrm{HCL}$ are prone to various infections, even with opportunistic or rare germs, as Kytococcus schroeteri, which induced a bacteremia in a recently published case [13]. This was the argument for prophylactic administration of filgrastim when our patient had neutropenia, during periods of increased epidemiological risk and when chemotherapy had no justification, in the absence of evidence of disease relapse.

The reduced compliance of the patient delayed the diagnosis of relapse, but we persevered and managed to convince her to cooperate and accept the bone marrow investigation. At that time we had no possibility to make an accurate flowcytometry examination in order to diagnose the relapse, due to lack of specific monoclonal antibody kits. In addition, an accurate flow cytometric gating of the large lymphocyte region is essential in order to detect low tumor burden [6], requiring an experienced examiner.

Our patient had 3 criteria for starting the treatment when HCL was diagnosed: the fever (probably of infectious nature), the presence of pancytopenia and the symptomatic splenomegaly [3]. Among the known prognostic factors, our patient presented at diagnosis splenomegaly ( $>10 \mathrm{~cm}$ below costal margin). Leucocytosis was not present. Unfortunately, we were not able to investigate the unmutated IgVH gene profile, the VH4-34 repertoire, and the TP53 gene mutation. No prognostic factor can modify the drug of firstline treatment, which is today pentostatin or cladribine. The purine analogues were not available in Romania in 2001. This is the reason for which our patient was treated with alpha-interferon, which was also indicated due to the presence of severe neutropenia and the presence of fever. Rituximab could be used instead of interferon, $375 \mathrm{mg} / \mathrm{m}^{2} \mathrm{IV}$ per week, during a month, as frontline monotherapy $[3,14]$, but it was not invented at that time. The response rate was only $82 \%$ (with 59 $\%$ complete hematological remissions) when it was used alone [15]. Purine analogs are indicated only after the correction of neutropenia. After a year, when neutropenia disappeared, we used cladribine that can also be administered in patients with kidney failure, unlike pentostatin [3]. Cladribine is a purine analog that inhibits adenosine deaminase. In this way, cellular processing of DNA is disturbed and the cell is prone to destruction. This new treatment was indicated due to the fact that complete remission, according to the definition of French Society of Haematology [3], was not obtained. It was not a surprise that cladribine was effective, knowing that complete response rates in classical HCL are up to 90\% [1], but it is also known that relapses appear frequently. The answer to purine analogues is not as good in patients with significant leukocytosis, bulky splenomegaly, or in the presence of an unmutated immunoglobulin variable heavy chain $(I g V H)$ gene profile, use of VH4-34 or with TP53 mutations [3]. In the first relapse, the diagnosis of HCL was confirmed and the patient was symptomatic. If our patient had not had TP53 gene or VH4-34 mutation, she would have had indication for nucleoside analogues in combination with rituximab, according to (3). If not - immunotoxins, BRAF inhibitors, bendamustine + rituximab (solutions that were and are not available in Romania) or, nucleoside analogues in combination with rituximab (3). We could not verify the presence of these mutations. She received cladribine, which was also efficient in the first relapse (this was an intermediate relapse - after a complete remission of 4 years), and in a second relapse, followed by rituximab, after a complete remission with a duration that cannot be specified due to the delay of bone marrow biopsy. In the first relapse it is indicated to search the presence of BRAF V600E mutation, that was detected recently, in 12 analysed cases of HCL, also using a immunohistochemical technique, relatively rapid and inexpensive, with $100 \%$ sensitivity and $100 \%$ specificity [8]. In the second relapse of disease, immunohistochemistry showed the presence of CD20+ cells, without which the approval of the National Commission for rituximab cannot be obtained in our country. According to the French Society of Hematology, rituximab is indicated in combination with nucleoside analogues in the first relapse of disease (3), but we used this combination only in the second relapse, due to the lack of immunohistochemistry at first relapse. Rituximab was added due to the known tendency to decreased responsiveness to chemotherapy in relapsed disease [16]. In a recent study made on 41 patients, the combination of purine analogs with rituximab conduced to a $100 \%$ response rate, even beyond frontline therapy [15]. Prospective clinical trials are needed to prove the superiority of purine analogs combined with rituximab, as first line therapy and in relapsed disease [15]. Thus, we were able to avoid the splenectomy (which were followed by a significant immune depression) and the alpha-interferon (which was tolerated with difficulty in the past), therapeutic modalities which can be indicated formally in these situations (3).

If they are available, other options for the relapsed disease are recombinant immunoconjugates directed towards CD22 (e.g. moxetumomab pasudotox), BRAF inhibitors such as vemurafenib [16] or dabrafenib, MEK inhibitors such as trametinib [17], and 
B cell receptor signaling kinase inhibitors such as ibrutinib [16]. Vemurafenib $(2 \times 240 \mathrm{mg}$ daily $)$ used in induction, followed by a maintenance treatment with $240 \mathrm{mg}$ once a day (after complete hematological remission) could also be useful to manage the relapsed HCL [2]. BRAF and MAK inhibitors were able to lead to the loss of HCL-specific gene expression signature [17]. Vemurafenib also normalized hematopoietic stem/progenitor cell frequencies, which have marked alterations in HCL [18]. Ibrutinib showed to be able to significantly inhibit HCL proliferation and cell cycle progression, the secretion of some chemokines and CXCL12-induced signaling [19].

In the pathway of HCL is involved BRAF V600E mutation, which increases the stimulation of mitogen-activated protein kinase signaling mechanism, implied in uncontrolled cell division [9]. In HCL were also found distinct molecular aberrations in the Raf/ MEK-ERK pathway [20], mutations as TP53 [3], ARID1A, EZH2, and recurrent inactivating mutations of the cell cycle inhibitor CDKN1B (p27). The last, which is also involved in senescence, is the second most frequent mutation in HCL and more common in HCL than in other cancers. In addition, nuclear factor kappa-light-chain-enhancer of activated B cells (NF-kB)-pathway is aberrantly activated in HCL, fact explained by the presence of many deregulated genes and multiple mechanisms [11]. There is the hope that these discoveries will soon become new therapeutic targets. The future will prove which of them will be more effective.

Most HCL patients have a very good long-term response to purine analogs, with or without an anti-CD20 monoclonal antibody such as rituximab [20].

There are authors who consider that at least $20-25 \%$ of HCL patients can be cured with only one treatment, according to an observational retrospective study on 144 patients with a median follow-up of 11.5 years [21]. But it is also known that about $30-40 \%$ of HCL patients relapse [20,22], that the study of minimal residual disease is important to detect the patients with such a possible evolution. Eight-color flow cytometry could be used for this purpose [22].

The monitoring of the evolution of our patient involves the early detection of possible infections, autoimmune diseases [23] or a new malignancy [24]. Patients with HCL, who have a dysfunctional immune response [23], are prone to develop one or more of these complications. In a survey made on 487 patients with HCL, 18\% presented a familial history of cancers, $8 \%$ were diagnosed with malignancies before HCL diagnosis and 10\% developed a second cancer after HCL was diagnosed [24]. The role of purine analogs in the appearance of a second malignancy is subject that deserves to be analyzed.

\section{Conclusion}

Due to the fact that the number of HCL patients is relatively small, multi-center studies are needed to assess the effectiveness of therapies against this lymphoproliferation.

Determination of minimal residual disease is essential for estimating the risk of relapse and to personalize the therapeutic conduct. It could predict who needs a single or multiple therapeutical lines.
The introduction of purine analogs in the treatment of HCL considerably improved the therapeutic response.

Monoclonal antibodies anti-CD20 (eg: rituximab) are a valuable discovery in both first-line treatment and in relapses, especially associated with purine analogs. Clinical trials are needed to confirm the superiority of this therapeutical combination compared to the use of only purine analogs.

There are hopes that new therapies will help to improve the therapeutic results. Some of them are under study (including vemurafenib or dabrafenib, moxetumomab pasudotox, trametinib or ibrutinib). We expect that others will be discovered, targeted towards different genetic mutations identified in HCL and molecules involved in the metabolic pathway of the disease.

An individual assessment of patient at diagnosis and during evolution is needed to determine which drug or drug combination is indicated and how many therapeutic lines are needed. The recent introduction of the association between cladribine and rituximab offers the opportunity to a stage analysis of the HCL treatment.

\section{Acknowledgement}

Thanks to the authors who have conducted research that allowed to advance our knowledge on the pathogenesis and treatment of HCL. The author apologizes researchers whose articles could not be mentioned due to the fact that the article could not be excessively long.

\section{References}

1. Grever MR, Blachly JS, Andritsos LA (2014) Hairy cell leukemia: Update on molecular profiling and therapeutic advances. Blood Rev 28: 197-203.

2. Bailleux C, Robert G, Ginet C, Re D, Thyss A, et al. (2014) Successful re-treatment of a relapsed $\mathrm{V} 600 \mathrm{E}$ mutated $\mathrm{HCL}$ patient with low-dose vemurafenib. Oncoscience 2: 44-49.

3. Cornet E, Delmer A, Feugier P, Garnache-Ottou F, Ghez D, et al. (2014) Recommendations of the SFH (French Society of Haematology) for the diagnosis, treatment and follow-up of hairy cell leukaemia. Ann Hematol 93: 1977-1983.

4. Monnereau A, Slager SL, Hughes AM, Smith A, Glimelius B, et al. (2014) Medical history, lifestyle, and occupational risk factors for hairy cell leukemia: the InterLymph Non-Hodgkin Lymphoma Subtypes Project. J Natl Cancer Inst Monogr 2014: 115-124.

5. Somasundaram V, Purohit A, Aggarwal M, Manivannan P, Mishra P, et al. (2014) Hairy cell leukemia: A decade long experience of North Indian Hematology Center. Indian J Med Paediatr Oncol 35: 271-275.

6. Yasuda H, Tsutsui M, Tanaka M, Araki M, Morishita S, et al. (2015) Accurate flow cytometric gating of the large lymphocyte region is a powerful screening method for detecting hairy cell leukemia presenting with a low tumor burden. Intern Med 54: 1287-1289.

7. Troussard X, Cornet É (2015) Chronic B-cell lymphoproliferative disorders with hairy cells. Ann Biol Clin (Paris).

8. Wang XJ, Kim A, Li S (2014) Immunohistochemical analysis using a BRAF V600E mutation specific antibody is highly sensitive and specific for the diagnosis of hairy cell leukemia. Int J Clin Exp Pathol 7: 4323-4328.

9. Ahmadzadeh A, Shahrabi S, Jaseb K, Norozi F, Shahjahani M, et al. (2014) BRAF Mutation in Hairy Cell Leukemia. Oncol Rev 8: 253.

10. Turakhia S, Lanigan C, Hamadeh F, Swerdlow SH, Tubbs RR, et al. (2015) 
Immunohistochemistry for BRAF V600E in the Differential Diagnosis of Hairy Cell Leukemia vs Other Splenic B-Cell Lymphomas. Am J Clin Pathol 144: 87-93.

11. Nagel S, Ehrentraut S, Meyer C, Kaufmann M, Drexler HG, et al. (2015) NFkB is activated by multiple mechanisms in hairy cell leukemia. Genes Chromosomes Cancer 54: 418-432.

12. Fattizzo B, Zaninoni A, Consonni D, Zanella A, Gianelli U, et al. (2015) Is chronic neutropenia always a benign disease? Evidences from a 5-year prospective study. Eur J Intern Med S0953-6205: 00184-00193.

13. Dietrich S, Hüllein J, Lee SC, Hutter B, Gonzalez D, et al. (2015) Recurrent CDKN1B (p27) mutations in hairy cell leukemia. Blood pii: blood-2015-04-643361.

14. Akinosoglou K, Melachrinou M, Makatsoris T, Sakellakis M, Papakonstantinou C, et al. (2015) Rituximab as frontline monotherapy in untreated hairy cell leukemia patients. Ann Hematol 94: 1069-1070.

15. Leclerc M, Suarez F, Noël MP, Vekhoff A, Troussard X, et al. (2015) Rituximab therapy for hairy cell leukemia: a retrospective study of 41 cases. Ann Hematol 94: 89-95.

16. Jain P, Polliack A, Ravandi F (2015) Novel therapeutic options for relapsed hairy cell leukemia. Leuk Lymphoma 1-9.

17. Pettirossi V, Santi A, Imperi E, Russo G, Pucciarini A, et al. (2015) BRAF inhibitors reverse the unique molecular signature and phenotype of hairy cell leukemia and exert potent antileukemic activity. Blood 125: 1207-1216.
18. Chung SS, Kim E, Park JH, Chung YR, Lito P, et al. (2014) Hematopoietic stem cell origin of BRAFV600E mutations in hairy cell leukemia. Sci Transl Med 6: 238ra71.

19. Sivina M, Kreitman RJ, Arons E, Ravandi F, Burger JA (2014) The bruton tyrosine kinase inhibitor ibrutinib (PCl-32765) blocks hairy cell leukaemia survival, proliferation and $B$ cell receptor signalling: a new therapeutic approach. Br J Haematol 166: 177-188.

20. Jain P, Pemmaraju N, Ravandi F (2014) Update on the biology and treatment options for hairy cell leukemia. Curr Treat Options Oncol 15: 187-209.

21. Zinzani PL, Stefoni V, Broccoli A, Pellegrini C, Gandolfi L, et al. (2014) Is it really possible to cure hairy cell leukemia patients only with frontline therapy? Ann Hematol 93: 1565-1569.

22. Garnache Ottou F, Chandesris MO, Lhermitte L, Callens C, Beldjord K, et al. (2014) Peripheral blood 8 colour flow cytometry monitoring of hairy cel leukaemia allows detection of high-risk patients. $\mathrm{Br} \mathrm{J}$ Haematol 166: 50-59.

23. Dasanu CA, Van den Bergh M, Pepito D, Alvarez Argote J (2015) Autoimmune disorders in patients with hairy cell leukemia: are they more common than previously thought? Curr Med Res Opin 31: 17-23.

24. Cornet E, Tomowiak C, Tanguy-Schmidt A, Lepretre S, Dupuis J, et al. (2014) Long-term follow-up and second malignancies in 487 patients with hairy cell leukaemia. Br J Haematol 166: 390-400.

Copyright: (c) 2015 Mihaila RG. This is an open-access article distributed under the terms of the Creative Commons Attribution License, which permits unrestricted use, distribution, and reproduction in any medium, provided the original author and source are credited. 